\title{
Choosing the right friends - predicting success of startup entrepreneurs and innovators through their online social network structure
}

\section{Peter A. Gloor*, Pierre Dorsaz, Hauke Fuehres and Manfred Vogel}

\author{
MIT Center for Collective Intelligence, \\ 5 Cambridge Center, \\ Cambridge, MA, 02139, USA \\ E-mail:pgloor@mit.edu \\ E-mail: pierre@swissnexboston.org \\ E-mail: hauke.fuehres@fhnw.ch \\ E-mail: manfred.vogel@fhnw.ch \\ *Corresponding author
}

\begin{abstract}
We compare the success of startup entrepreneurs and innovators with their social networking behaviour. In particular, we analyse the LinkedIn, Facebook, and e-mail networks of swissnex Boston, Switzerland's science and technology outpost in Boston, connecting Swiss and US entrepreneurs and academics. In our analysis, we focus on the participants of two Swiss entrepreneurship-coaching programmes, venture leaders and VentureKick. We find that the more central actors are in the different types of networks, the more successful they are, proximity to key people also correlates with success. In addition, we detect indicators for the key role of ETH Zurich for the creation of new startups. On the theoretical side, we add to emergent research comparing online networks to real-world networks, confirming the value of pre-existing social capital acquired attending a selective university. On the practical side, our results have key implications for entrepreneurs, venture capitalists, and organisers of entrepreneurship coaching programmes.
\end{abstract}

Keywords: entrepreneurship; social network analysis; online social network; LinkedIn; Facebook; XING; swissnex; venture leaders,; VentureKick.

Reference to this paper should be made as follows: Gloor, P.A., Dorsaz, P., Fuehres, H. and Vogel, M. (2013) 'Choosing the right friends - predicting success of startup entrepreneurs and innovators through their online social network structure', Int. J. Organisational Design and Engineering, Vol. 3, No. 1, pp.67-85.

Biographical notes: Peter A. Gloor is a Research Scientist at the MIT Center for Collective Intelligence and Chief Creative Officer of social media software company galaxyadvisors. He is also an Honorary Professor at the University of Cologne, Lecturer at Aalto University, and Distinguished Visiting Professor at the Universidad Catolica Santiago de Chile.

Pierre Dorsaz is a Project Manager at swissnex Boston, Switzerland's first science and technology consulate in Boston. The mission of swissnex is to 'connect the dots' between Switzerland and New England by fostering collaborations in the fields of entrepreneurship, innovation and academic research. 
Hauke Fuehres received his Diploma in Information Systems from the University of Cologne. He was a visiting student at MIT and worked at the University of Applied Sciences Northwestern Switzerland. Besides academia, he has worked for companies in Switzerland, the USA and Germany.

Manfred Vogel is currently the Head of the Computer Science Department at the University of Applied Sciences Northwestern Switzerland, teaching efficient algorithms in the Bachelor programme and optimisation in the Master programme. He is the founder and former Head of the Institute of 4D-Technologies. His research area is algorithmic and combinatorial optimisation, and information retrieval in combination with machine learning. Prior to this, he worked for a decade in astrophysics, in particular on the modelling of symbiotic stars. He received his Master in Mathematics and his $\mathrm{PhD}$ in Theoretical Physics from ETH Zurich.

\section{Introduction}

Entrepreneurs have long considered interpersonal networking key for promoting their new ideas, especially in high tech circles. This has been confirmed by an active stream of research (Porter et al., 2005; Baum et al., 2000; Mehra et al., 2006). More and more of this networking activity is shifting towards the virtual world. Communication through online social networks, such as Facebook, LinkedIn, Twitter, MySpace and blogs has become a major means of staying in touch with friends and business partners, complementing, and even substituting established communication channels such as e-mail and phone (Ellison et al., 2007). This increase in online social communication leads to the question: Do the business benefits of social ties extend to online social networking?

In this project, we compare the professional success of startup entrepreneurs and academics with their social networking behaviour. In particular, we analyse the social network of the swissnex Boston community. swissnex Boston is the Consulate of Switzerland in the Boston area, dedicated primarily to education, research, and innovation. swissnex Boston is part of a network of five science and technology outposts in the USA (Boston and San Francisco) and Asia (Singapore, Shanghai and Bangalore) run by the Swiss State Secretariat for Education and Research. One of its key objectives is to support the activities of Swiss scientists, researchers and startup entrepreneurs in the Boston area by assisting them to build their networks and exchange knowledge with their local counterparts. In addition, we also measure the effectiveness of 'VentureKick', a startup funding programme for Swiss early-stage entrepreneurs with a promising technology, and 'venture leaders', a ten-day intensive business development 'bootcamp' for Swiss entrepreneurs held in the Boston area.

By mapping the interactions within a business-networking organisation, our analysis will allow such organisations to come up with new ways to more efficiently connect its members. By analysing the networking behaviour of participants in early-stage incubators, we also develop recommendations for organisations supporting startup entrepreneurs. The study will be a useful management tool for such emergent and mostly 
virtual organisations by giving tangible measures of its relationship-building activities, which can then be communicated to its stakeholders. On the practical level, our research makes the contributions of programmes for early-stage entrepreneurs, such as venture leader, VentureKick, and swissnex Boston, more measurable in order to assess and improve the efficiency of their community-building efforts, and to analyse the impact of their programmes for each segment of their community.

\section{Background}

A wide body of research has revealed what type of network might be indicative of and even supportive for successful entrepreneurs (Porter et al., 2005; Baum et al., 2000). So far, most of this analysis is based on 'face-to-face' networks. These face-to-face networks were constructed by different means. One way to model ties was the so-called interlocking directorates of board members, where two different companies have a tie if the same director sits on the boards of both companies. Benefits of this construct were seen as far back as Imperial Germany (Fohlin, 1999). A second type of network is the supplier-manufacturer relationship, where Uzzi (1997), studying a sample of apparel manufacturers in New York, discovered the 'paradox of embeddedness', meaning that being embedded into a close-knit group of entrepreneurs is good for business performance - up to a point, after which the entrepreneur loses flexibility in the case of external shocks such as an economic crisis. On the other hand, alumni networks seem to provide a powerful knowledge advantage for mutual fund managers. Cohen et al. (2008) found that fund managers preferably bought stock of companies whose board members were alumni of the same university, and they also achieved higher returns on those investments compared to their average portfolio. Another way to construct networks is through the strategic alliances between firms. Schilling and Phelps (2007) found that firms with high clustering and high reach to other companies were more innovative than others. Raz and Gloor (2007), looking at Israeli software startups, found that startups whose founders had more formal and informal ties had a higher chance to survive the burst of the e-business bubble.

While all of these links are collected in the 'brick and mortar' world, online social networking is becoming increasingly important also for business. Networks such as LinkedIn and its German sibling, XING, are seen as essential business tools for executive recruiters, human resources administrators, sales and marketing managers and startup entrepreneurs (O’Murchu et al., 2004). In earlier work, Nann et al. (2010) found a correlation between central network position of entrepreneurs in XING and their business success. Meanwhile, a more differentiated picture emerged, where having too many online friends might be detrimental to longtime startup success. Frequently, social business networks act as a substitute for a Rolodex. They signal that there is a likelihood two people might know each other, without any indication about the strength of the tie. This might be different for links where external indicators predict a strong tie, for example if people connected in LinkedIn, are alumni of the same selective university or entrepreneurship programme. All this apparently contradictory evidence warrants further research. 


\section{Method}

We are comparing the online social networks of entrepreneurs and innovators in LinkedIn, FaceBook, XING, and e-mail with their success. In particular, we focus on the social networks among participants in swissnex networking events. Since the mission of swissnex Boston consists of nurturing connections among Swiss and US innovators, our approach was to analyse the networks brokered by the efforts of swissnex staff. The links between swissnex Boston, venture leaders, and VentureKick are many. The venture leaders programme, a ten-day entrepreneurship 'bootcamp' in Boston, is co-organised and hosted by swissnex Boston. A significant proportion of VentureKick-funded members also participates in venture leaders, or might have visited swissnex Boston on their own. Collecting the LinkedIn, Facebook and XING networks of entrepreneurs, academics and researchers allow us to compare their centrality in the social network and their proximity in the network to key swissnex Boston staff members with their success.

Using e-mail, we conducted a survey with 500 close contacts of swissnex. Producing a response rate of $28 \%, 39$ Swiss entrepreneurs, 23 US entrepreneurs, 36 Swiss academics, and 41 US academics answered the survey. We also asked the participants to share their LinkedIn and Facebook networks, obtaining LinkedIn networks from 72 respondents with a total of 15,913 actors, and Facebook networks from 31 respondents with a total of 6,928 actors. In addition we also collected 28,152 anonymous e-mail headers from April 25, 2011 to October 2, 2011, from e-mail traffic at swissnex.

We compared the success of the entrepreneurs and academics with their social network position in the Facebook, LinkedIn, XING, and swissnex e-mail networks. Success was measured in three ways. First, by manually evaluating entrepreneurs and academics on the web, looking at their Facebook page, LinkedIn page, Google Scholar listings, company websites, and any other online sources we could find. This evaluation is described below. Second, using the same rating, the managing director of venture leaders evaluated the business success of the companies founded by 184 participants in the venture leaders programme. Third, we used the amount of funding that 268 participants in the VentureKick programme obtained from VentureKick, ranging from 5,000 to 30,000 Swiss Franc as a very early benchmark for the future chances of success of their business ventures.

Table 1 Evaluation of professional success of entrepreneurs and academics

\begin{tabular}{lcc}
\hline $\begin{array}{l}\text { Success } \\
\text { level }\end{array}$ & Description entrepreneurs & Description researcher \\
\hline 1 & $\begin{array}{c}\text { Company bankrupt / website not } \\
\text { existing / side business }<1 \text { year } \\
\text { Company in business }<\text { five years } / \\
\text { side business }\end{array}$ & Zero papers in Google Scholar \\
2 & $\begin{array}{c}\text { Small or medium size business }> \\
\text { five years / main income / successful } \\
\text { Medium size / family business/ } \\
\text { stable / very successful }\end{array}$ & Two to five papers in Google Scholar \\
4 & $\begin{array}{c}\text { Large company / highly successful } \\
\text { projects / external funding / rewards }\end{array}$ & Five to ten papers in Google Scholar \\
& &
\end{tabular}


Table 1 shows our definition of the professional success of entrepreneurs and academics that was used as the basis for the manual evaluation. We also did an evaluation of the individual job level that each person reported (Table 2).

Table 2 Evaluation of individual success of entrepreneurs and academics

\begin{tabular}{lcc}
\hline Success level & Description entrepreneur & Description academic \\
\hline 1 & Specialist, manager & Grad student \\
2 & Senior executive, management team & Post-doc \\
3 & CEO & Prof/senior researcher \\
\hline
\end{tabular}

Figure 1 shows the distribution of success of the 226 people who were manually rated. We chose the 100 most central people by betweenness centrality and by degree centrality (Wasserman and Faust, 1994) in the LinkedIn and the Facebook networks. Eliminating the duplicates from these 400 names lead to 226 different people. Combined success was calculated as the product of professional success and individual success defined in tables 1 and 2, to give a combined metric of the prestige of a person derived both from the prestige of the employer and the individual job title. An interrater reliability analysis using the Kappa statistic (Landis and Koch, 1977) was performed to determine consistency among raters with Kappa $=0.52 * * *(\mathrm{~N}=77)$.

Figure 1 Distribution of combined success among participants $(\mathrm{N}=226)$ (see online version for colours)

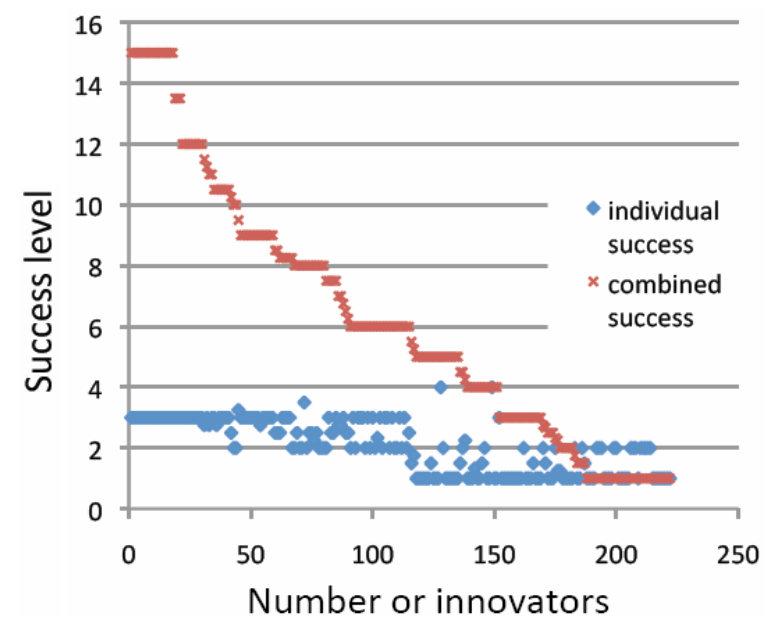

As Figure 1 shows, combined success is exponentially distributed among the swissnex-affiliated entrepreneurs, with very few entrepreneurs and academics being considerably more successful than the rest. In the remainder of this paper, we will investigate whether the position in the social network bears any relation with the combined success of the individual academic or entrepreneur. 


\section{Analysing the LinkedIn network}

We found that the LinkedIn and Facebook networks exhibit substantial differences. The LinkedIn network is clearly focused on business use. swissnex Boston extensively uses LinkedIn as one of its contact-management tools in its daily operations: to keep in touch with existing contacts, to find relevant people for its upcoming activities and events and for its outreach campaign. Figure 2 shows the LinkedIn network of all respondents. Pink dots are the people who are either swissnex staff or relations from the swissnex staff. Purple dots are either Swiss entrepreneurs or their relations. Brown dots are either US entrepreneurs or their relations. Green dots are Swiss researchers or their relations. Blue dots are US researchers or their relations. Figure 2 shows that there is a noticeable split between Swiss and US entrepreneurs, with the Swiss academics (green) 'bridging structural holes' between Swiss entrepreneurs (purple) and US entrepreneurs (brown), while the US academics (blue) are fairly isolated. The fact that Swiss entrepreneurs' networks tend to cluster can be explained by their participation in the diverse entrepreneurship programmes launched by swissnex over the past ten years, such as the venture leaders programme. The swissnex staff members (pink dots) clearly act as connectors, bringing together the members of the four diverse groups.

Figure 2 Social network of LinkendIn respondents $(\mathrm{N}=72)$ (see online version for colours)

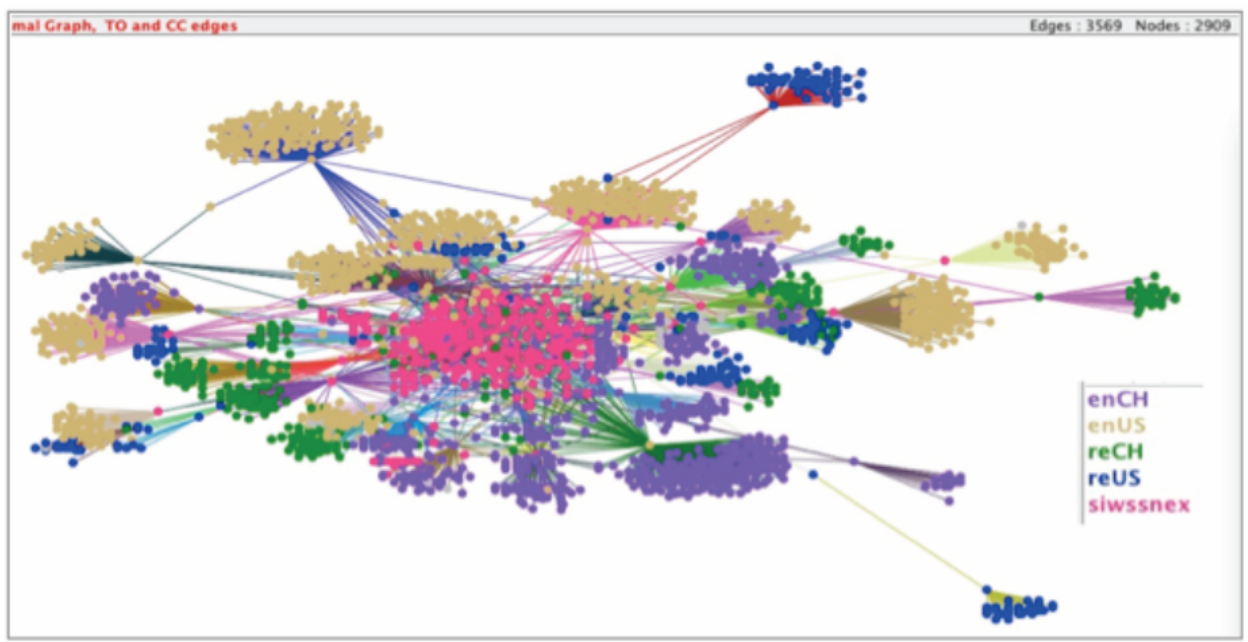

The social network position in the LinkedIn network predicts the success of an academic or entrepreneur. Being more central in the LinkedIn network is an indicator of success both for degree ${ }^{1}\left(\mathrm{R}=0.238^{* * 2}\right)$ and betweenness $\left(\mathrm{R}=0.199^{*}\right)$ centrality (Wasserman and Faust, 1994). This means that the more central a person is in the network, the more successful s/he is. This also means that swissnex succeeded in building up a network of successful people. However, this does not answer the question of causality: are people more successful because they are central in the network, and thus close to the swissnex staff, or are they more central because they are successful? We speculate that both assumptions are partly true: more successful people are more sought out as networking partners, and, thus, are more central in the business network. The central presence of 
successful people will also facilitate and improve - through mentoring, coaching and networking activities - the professional development of researchers and entrepreneurs and, therefore, increase their centrality over time.

\section{Analysing the Facebook network}

In contrast to the LinkedIn network, the Facebook network is more scattered and spread out. There is no clustering among the four categories (US and Swiss entrepreneurs, US and Swiss academics). The core part of the network-clustering around members of the swissnex staff is also less dense compared to the LinkedIn network. Nevertheless, the blue cluster in the centre around the swissnex director is somewhat more crowded than the rest (Figure 3). Most people use Facebook differently from LinkedIn, making a distinction between managing their business contacts in LinkedIn and their private friends in Facebook. This is reflected in the larger number of entrepreneurs and academics we were able to identify and evaluate in the LinkedIn network, 131 out of 226 looked up, as compared to the Facebook network where we were only able to identify and evaluate 81 entrepreneurs and academics.

Figure 3 Social network of Facebook respondents $(\mathrm{N}=31)$ (see online version for colours)

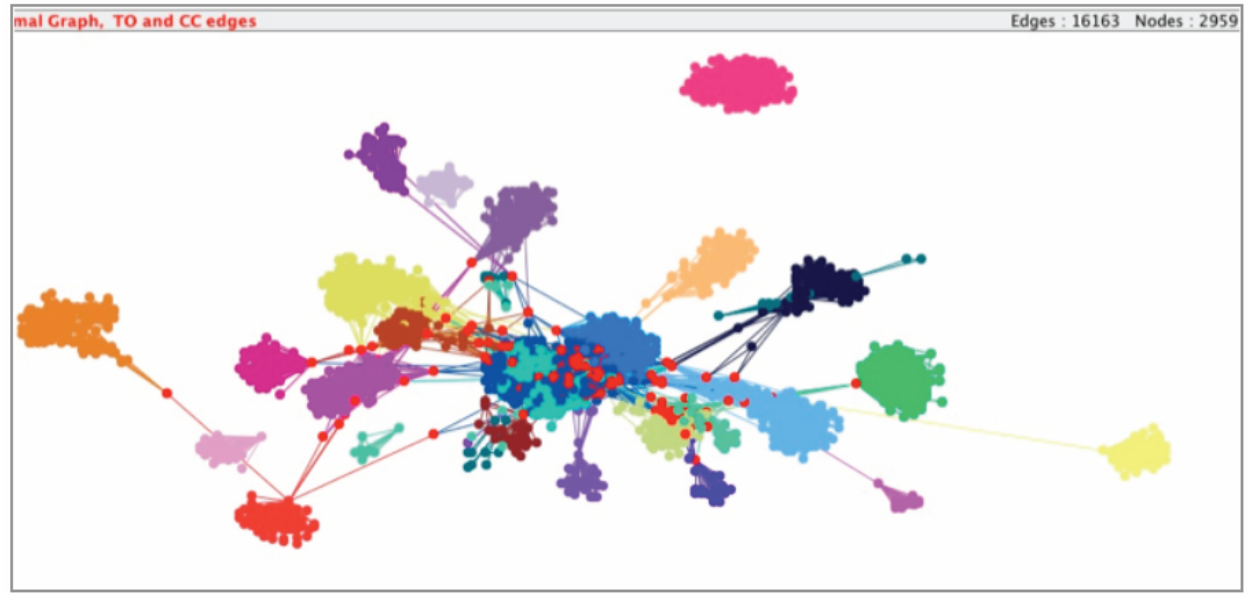

More central people in the Facebook network seem to be somewhat more successful, but the correlations are rather weak and non-significant. Degree centrality in the Facebook network has no predictive power at all, which means that the number of Facebook friends does not predict the business or academic success. Betweenness centrality position in the Facebook network is a somewhat better predictor of individual success, although it is not significant $(\mathrm{R}=0.126, \mathrm{p}=0.264)$. This may suggest that at least a few people are using Facebook to manage their professional contacts, just like in LinkedIn, but the large majority of the people polled tend not to mix their private and professional connections. 


\section{Analysing the combined LinkedIn and Facebook network}

Therefore, we speculate that the combined LinkedIn and Facebook network, created through combining the 72 LinkedIn networks with the 31 Facebook networks, might offer the best predictive power to measure individual success. Figure 4 shows the combined network. Due to the strong clustering effect of the LinkedIn network, the swissnex staff members also appear in the centre of the combined network. The social networks of the Swiss entrepreneurs (lighter blue) and the US entrepreneurs (pink) are the most dominant; although, they again have little overlap, US entrepreneurs are in the top half of the graph, and Swiss entrepreneurs in the bottom half. Swiss researchers (dark blue) and US researchers (green) are scattered throughout the network, while their absolute number is relatively small. Visually, the US entrepreneurs and their networking friends seem to be the strongest group. The number of uploading US entrepreneurs was relatively small, which indicates that the average LinkedIn network of an US entrepreneur is larger than the one of their Swiss counterparts. Entrepreneurs also seem to have larger networks than academics or at least use online social networking more intensively. Anecdotally, the increasing use of social media by early-stage companies for marketing explains this difference. The ready availability of social networking at low cost has led entrepreneurs to widely use these platforms for their business activities.

Figure 4 Social network of combined Facebook and LinkedIn profiles (103 separate networks combined), 24,176 actors, 70,924 edges, coloured by role (top 2,592 actors shown) (see online version for colours)

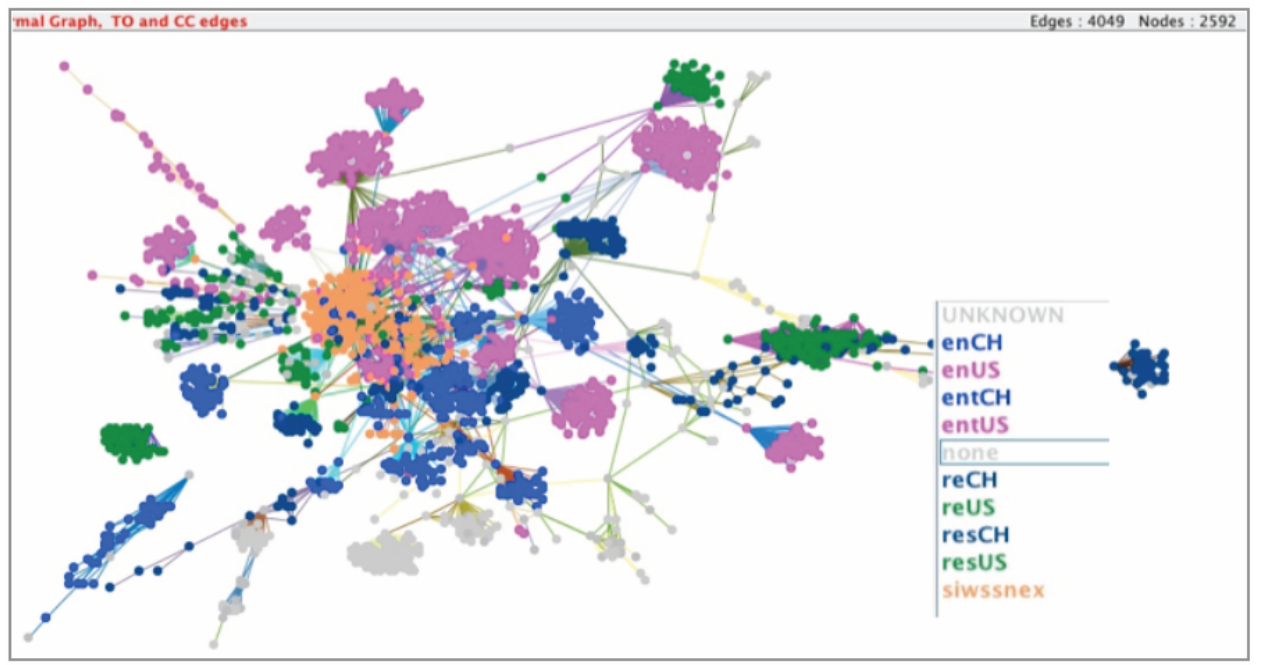

It turns out that the combined LinkedIn and Facebook network is the best indicator of success: the more friends an actor has in this network, the more individual success $\mathrm{s} / \mathrm{he}$ has $\left(\mathrm{R}=0.409^{* *}, \mathrm{~N}=131\right)$. We also calculated the correlations for the separated samples of academics and entrepreneurs, respectively. Although the effect is stronger for academics $\left(\mathrm{R}=0.371^{*}\right)$ than for entrepreneurs $(\mathrm{R}=0.166$, non-significant $)$, both samples show the same behaviour. Again, this does not answer the question of causality: are people more central because they have been successful in the past, or will they become even more successful because they are central in the swissnex network? Based on prior 
work doing an longitudinal analysis in a German entrepreneurship network (Nann et al., 2010), we suspect a combined effect: more successful people know about the value of business networking, and, therefore, will spend more time connecting to potential academic collaborators and business partners, while being actively courted and contacted by other participants at swissnex events. Therefore they will be more central in the swissnex network. On the other hand, through their more active networking, they can also expect to become more successful in their entrepreneurial and academic ventures.

\section{Analysing the e-mail network of swissnex}

To better understand the dynamics of collaboration at swissnex, we collected 28,152 anonymous e-mail headers from April 25, 2011 to Oct 2, 2011 from swissnex e-mail traffic. To respect privacy, we only looked at senders, receivers, and timestamps. Figure 5 shows the results. The top picture displays the full network of all people at swissnex, only including those who exchanged at least two e-mail messages - an easy way of getting rid of e-mail spam.

One surprising result was that the overlap between key people in the e-mail archive, and people in the Facebook and Linkedin networks was rather small: of the top 226 Facebook and Linkedin people we looked up and ranked by success, only 67 were in the e-mail archive. This shows that the work network, indicated by e-mail exchange, and the social network of swissnex customers in LinkedIn and Facebook, are two rather separate worlds.

Figure 5 (a) Full e-mail network, all people who have exchanged at least two e-mails (b) E-mail network, only people who have exchange at least 30 e-mails (see online version for colours)

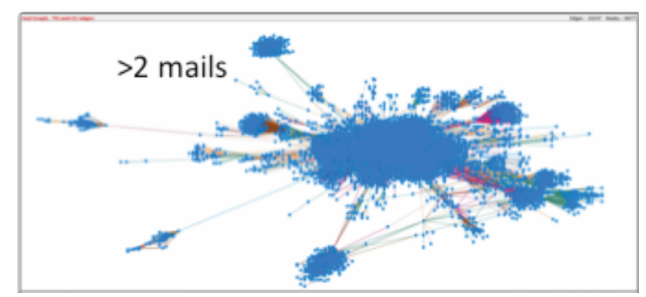

(a)

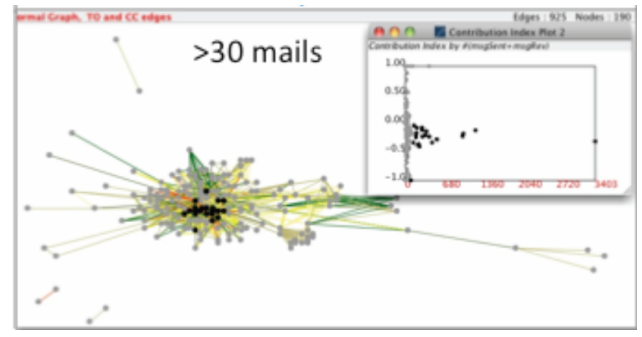

Notes: Black nodes are Swissnex staff members. Small inset window at bottom is contribution index, showing e-mail activity of each actor (x-axis) and how much of a sender (top of y-axis) or receiver (bottom of y-axis) a person is.

Source: Gloor et al. (2003) 
We then analysed success of the 67 actors we were able to find in the list of the 226 people whose success we had measured. While there are weak correlations between individual success and betweenness centrality and degree centrality, they are not significant.

\section{Measuring entrepreneurship and academic success by proximity to key influencers}

To better understand the role of key networkers at swissnex, we define the new metric of 'proximity' to key influencers, people whose friendship we consider beneficial to business success, a prominent person in a position to coach and support entrepreneurs and academics. We measure the social distance from them to all the other people in the LinkedIn, Facebook, and e-mail networks. We are looking to find a negative correlation between proximity and business success: i.e., the smaller proximity is and the closer people are to the key influencer, the more successful they may be. In other words, proximity is the number of networking steps it takes a person to reach the key influencer.

Table 3 Correlations between proximity to key influencers and entrepreneurial or academic success

\begin{tabular}{|c|c|c|c|c|c|c|c|}
\hline Distance to: & & $\begin{array}{c}\text { Facebook } \\
\text { combined } \\
\text { success }\end{array}$ & $\begin{array}{c}\text { Facebook } \\
\text { individual } \\
\text { success }\end{array}$ & $\begin{array}{c}\text { LinkedIn } \\
\text { combined } \\
\text { success }\end{array}$ & $\begin{array}{c}\text { LinkedIn } \\
\text { individual } \\
\text { success }\end{array}$ & $\begin{array}{c}\text { E-mail } \\
\text { combined } \\
\text { success }\end{array}$ & $\begin{array}{c}\text { E-mail } \\
\text { individual } \\
\text { success }\end{array}$ \\
\hline \multirow[t]{3}{*}{ Director } & $\begin{array}{l}\text { Pearson } \\
\text { correlation }\end{array}$ & -.140 & -.078 & -.153 & $-.214^{*}$ & -.167 & -.144 \\
\hline & $\begin{array}{l}\text { Sig. } \\
\text { (two-tailed) }\end{array}$ & .316 & .580 & .091 & .017 & .237 & .308 \\
\hline & $\mathrm{N}$ & 53 & 53 & 123 & 123 & 52 & 52 \\
\hline \multirow[t]{3}{*}{$\begin{array}{l}\text { Startup- } \\
\text { advisor }\end{array}$} & $\begin{array}{l}\text { Pearson } \\
\text { correlation }\end{array}$ & -.144 & -.103 & $.228^{*}$ & .100 & -.061 & -.053 \\
\hline & $\begin{array}{l}\text { Sig. } \\
\text { (two-tailed) }\end{array}$ & .304 & .461 & .011 & .270 & .666 & .708 \\
\hline & $\mathrm{N}$ & 53 & 53 & 123 & 123 & 52 & 52 \\
\hline \multirow[t]{3}{*}{$\begin{array}{l}\text { Academic- } \\
\text { advisor }\end{array}$} & $\begin{array}{l}\text { Pearson } \\
\text { correlation }\end{array}$ & -.204 & -.158 & .145 & .174 & .174 & .076 \\
\hline & $\begin{array}{l}\text { Sig. } \\
\text { (two-tailed) }\end{array}$ & .143 & .258 & .109 & .055 & .216 & .592 \\
\hline & $\mathrm{N}$ & 53 & 53 & 123 & 123 & 52 & 52 \\
\hline \multirow[t]{3}{*}{$\begin{array}{l}\text { VentureKick } \\
\text { director }\end{array}$} & $\begin{array}{l}\text { Pearson } \\
\text { correlation }\end{array}$ & & & -.043 & -.160 & -.074 & -.254 \\
\hline & $\begin{array}{l}\text { Sig. } \\
\text { (two-tailed) }\end{array}$ & & & .633 & .077 & .601 & .069 \\
\hline & $\mathrm{N}$ & & & 123 & 123 & 52 & 52 \\
\hline \multirow[t]{3}{*}{ Customer 1} & $\begin{array}{l}\text { Pearson } \\
\text { correlation }\end{array}$ & .142 & .198 & $-.206^{*}$ & $-.250^{* *}$ & -.239 & $-.315^{*}$ \\
\hline & $\begin{array}{l}\text { Sig. } \\
\text { (two-tailed) }\end{array}$ & .311 & .156 & .022 & .005 & .087 & .023 \\
\hline & $\mathrm{N}$ & 53 & 53 & 123 & 123 & 52 & 52 \\
\hline
\end{tabular}


Table 3 lists the results. Proximity to the swissnex director is beneficial for people in all three networks: LinkedIn, Facebook and e-mail, although the effect is strongest for the LinkedIn network $(\mathrm{R}=-0.200 *)$. On the other hand, people close in the LinkedIn network to the academic advisor and the startup advisor are less successful than people farther away. The opposite is true for the Facebook network, where people with smaller proximity, i.e., who are closer to the academic advisor and the startup advisor, are more successful. This might suggest that many people who are searching LinkedIn-connections to the academic advisor and the startup advisor have just begun their careers. The VentureKick director, however, shows the same positive effect as the swissnex director, in that innovators closer to him in the e-mail and LinkedIn networks are more successful, although none of the correlations are significant.

People close to the director have a higher success rate than the contacts of the advisors; this may be partially explained by the director's level of seniority. The director has been at swissnex for the last ten years, while the advisors' tenure on average is two to three years. His longevity in this position strengthens the predominant role of the director and the importance for academics and entrepreneurs to directly connect with him to better gain access to the Boston area business ecosystem.

We identified an active swissnex participant (customer 1 in Table 3 ) - both academic and entrepreneur - who is not a staff member of swissnex. People in his proximity in the LinkedIn and e-mail networks are significantly more successful $(\mathrm{R}=-.250 * *$ for Linkedin, $\mathrm{R}=-.315^{*}$ for e-mail) than people less close to him. The opposite is true, however, for his Facebook network. People close to him are less successful than people further away in the network. It therefore seems that he uses LinkedIn (for managing business contacts) and Facebook (for his private friends) in very different ways, not choosing his friends for their business success.

This suggests that there is quite a difference in the way different people use LinkedIn and Facebook networks. It seems that some swissnex staff members, such as the director, use Facebook for managing their professional relationships, like LinkedIn; however, individual correlations are lower than for the LinkedIn proximities. But, the swissnex customer1, whose LinkedIn proximity is a strong predictor of success for the people close to him, showed the opposite effect in the Facebook network with proximity to him predicting less business success.

Many swissnex customers are not yet successful when they enter the network but rely on swissnex networking activities to boost their career, that is increase in centrality also leads to further success. Since one of the core mission of swissnex is to support young academics and early stage entrepreneurs, people from those categories seek to connect with the swissnex team to improve their chances to succeed and enjoy the opportunity to network with successful people with high centrality. That provides first indications towards answering the thorny question of causality: people want to become more 'central' to be successful.

\section{Measuring the success of entrepreneurship programmes}

We obtained two datasets of Swiss startup entrepreneurs participating in entrepreneurship training programmes: 268 participating in the VentureKick programme (http://www. venturekick.ch/) and 184 participants of the venture leader programme (http://www. venturelab.ch/ventureleaders). The VentureKick programme is financed by five Swiss 
foundations (Avina Stiftung, Ernst Göhner Stiftung, Foundation 1796, Gebert Ruef Stiftung, OPO-Stiftung), giving up to 130,000 Swiss Francs to each applicant in increments of 5,000 to 10,000 Swiss Francs. Our metric of success for the VentureKick participants is the amount of money, from 5,000 to 30,000 Swiss Francs that each participant obtained.

Established in 2000 and financed by the Swiss Commission for Technology and Innovation CTI, the venture leaders programme takes about 20 Swiss entrepreneurs to its annual ten-day entrepreneurship training and immersion programme to Boston. The business success of 184 past participants has been ranked by one of the managing directors of the programme on a score of 1 (worst) to 5 (best), allowing us to compare their business success with their networking behaviour.

\subsection{Constructing the founder network}

We are constructing a social network of founders through the German business networking site XING. Out of the 184 participants in the venture leaders programme, we were able to find 97 in the XING network. We added another 68 Swiss founders who are self-declared as Swiss entrepreneurs in XING. Figure 6 shows the combined XING Venture Leaders and Swiss founders social network. Each dot is a person, and each connecting line is the XING link between two people (they might have chosen to hide the link to the public, in this case it remains invisible to us).

Figure 6 Social network among self-declared Swiss startup on XING (see online version for colours)

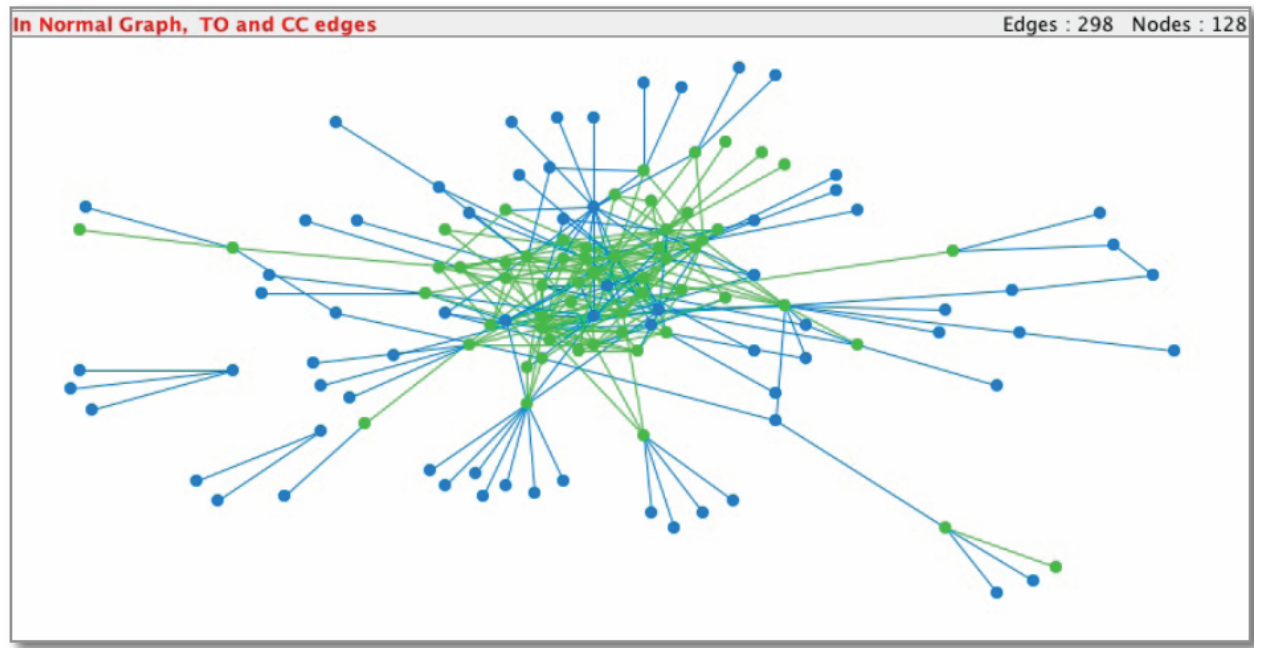

Notes: Green nodes are venture leaders participants, blue nodes are non-venture leaders Swiss founders who self-declared as such in XING. Non-connected entrepreneurs are not shown.

We found no significant correlation between degree centrality (number of friends) and betweenness centrality in the founder network from Figure 6. This means that a prominent position in this founder network does not seem to indicate any economic advantage. 
Studying the network in Figure 6 suggests a prominent role for founders of startups who are also alumni of ETH Zurich, the Swiss Federal Institute of Technology, one of Europe's leading technology universities. We therefore decided to split the founders and their social networks into two groups: ETH-affiliated founders and non-ETH-affiliated founders. Figure 7 shows the full network of all entrepreneurs from ETH and their friends.

Figure 7 XING social network of ETH alumni $(\mathrm{N}=1784)$ (see online version for colours)

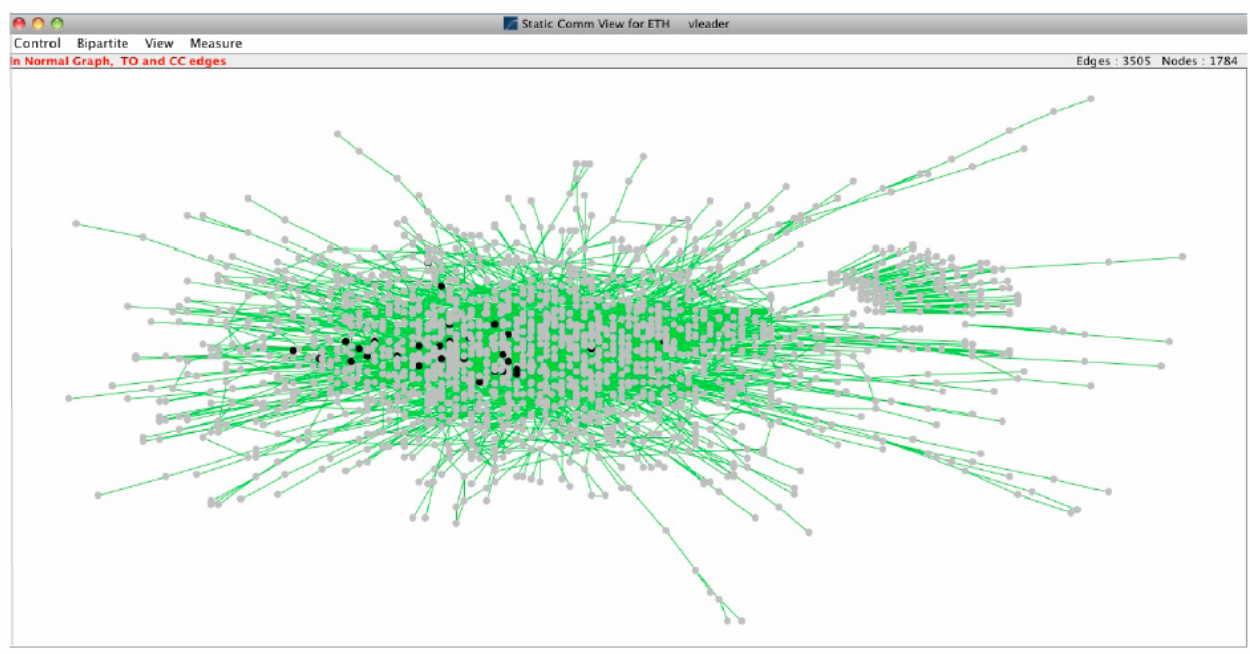

Note: Black dots are entrepreneurs.

Each of the 1,784 actors shown in Figure 7 is an ETH alumnus, the black dots are the ETH-affiliated founders from Figure 6. Figure 8 shows the same picture for the 9,154 non-ETH-affiliated founders and their XING friends, who are affiliated with one of the other 13 Swiss universities.

Figure 8 XING social network of Swiss university alumni, only non-ETH alumni shown $(\mathrm{N}=9,154)$ (see online version for colours)

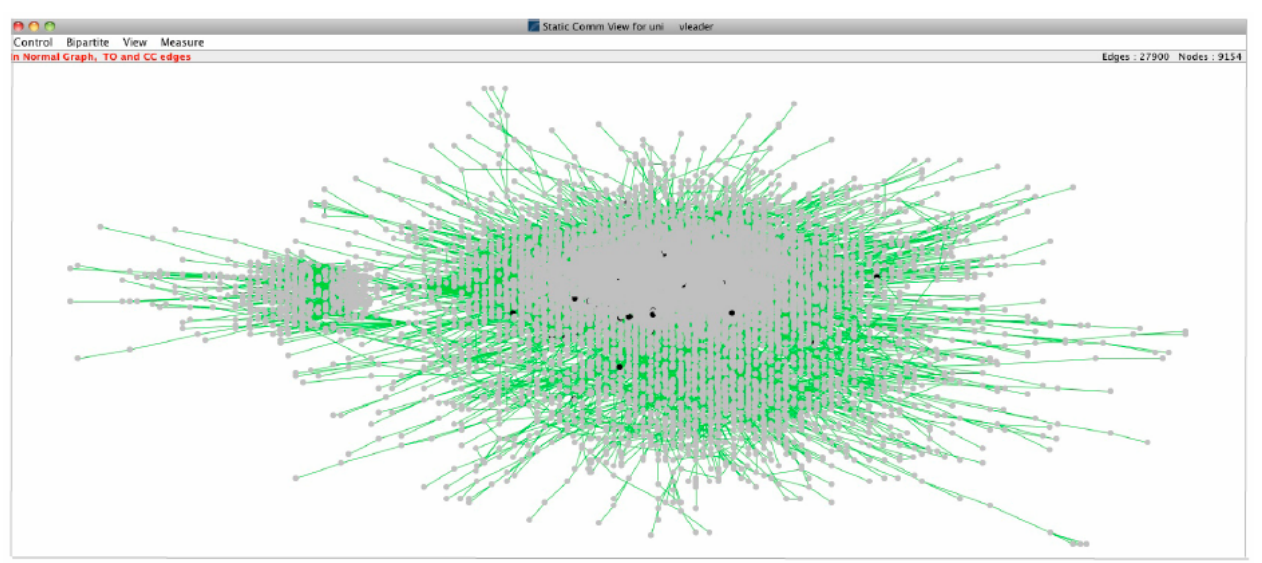

Note: Black dots are entrepreneurs. 
As the subsequent analysis in this section shows, being in XING, being central in the XING social online network, being close to prominent Swiss venture capitalists, being an alumnus from ETH and being well-connected within the ETH-alumni network are all predictors of startup entrepreneur success.

\subsection{Swiss entrepreneurs close to key venture capitalists are more successful}

In the Swiss founder network shown in Figure 6, we measured the same proximity of entrepreneurs from two Swiss venture capitalists as we did for the swissnex director described in Section 8. We found that the more negative the correlation is, that is the shorter the distance from venture capitalists to entrepreneur, the more successful is the entrepreneur. This means, even if an entrepreneur does not have direct contact to the venture capitalist, $\mathrm{s} /$ he is still more successful if $\mathrm{s} / \mathrm{he}$ is surrounded by other entrepreneurs with direct access to the venture capitalist. This is not surprising, since the main task of a venture capitalist is to 'discover' successful entrepreneurs. Somewhat surprisingly we found that proximity to $\mathrm{VC1}$, a famous investor in Switzerland, is less successful in predicting promising startups $(\mathrm{R}=-.254, \mathrm{p}=.081)$ than proximity to $\mathrm{VC} 2\left(\mathrm{R}=-317^{*}\right)$, a less widely-known 'business angel'. Although on average, the VC1-distance is smaller (because he is widely known and entrepreneurs want to be his XING friends), its relative shortness is a weaker predictor than the more stretched out VC2-distance to 'business angel' VC2.

For comparison we also measured the predictive power of all founders' proximity to the most central entrepreneur in the social network displayed in Figure 6. Proximity to him does not convey any economic advantage.

In the next four sections (9.3 to 9.6) we compare the mean individual success levels measured by the score in table 1 between the different populations:

1 venture leader participants

2 VentureKick participants

3 swissnex customers

4 Swiss entrepreneurs with a XING profile

5 Swiss entrepreneurs who are ETH alumni.

\subsection{Participation in both venture leaders and VentureKick is mutually reinforcing}

Among the 134 success-ranked venture leaders there are 35 VentureKick participants. Compared to the other 99 venture leader participants' score of $3.11(\sigma=1.27)$, these 35 entrepreneurs have a mean success score of 3.69 (with standard deviation $\sigma=0.87$, T-test significant on the 0.01 level).

The same is also true the other way around: among the 268 VentureKick participants, there are 35 venture leaders. These venture leaders also got more money from VentureKick, namely a mean amount of 22,286 Swiss Francs $(\sigma=8255)$ compared to a mean amount of 11,352 $(\sigma=7932)$ Swiss Francs for the other 233 VentureKick participants (T-test significant on the 0.01 level). 
Therefore, it seems that both the venture leader and the VentureKick selection boards have a knack for choosing successful candidates. To put it in other words, participating in both programmes seems to be mutually reinforcing: it pays off for the entrepreneurs to take part in both the venture leader and VentureKick programmes, leading to getting more startup money, and being a more successful founder.

\subsection{Swissnex customers who are also participants in startup programmes VentureKick or venture leaders are more successful}

Out of the 225 success-ranked swissnex customers there are 11 VentureKick and ten venture leader participants. They both stand out among the Swissnex customers, with a mean success score of $2.75(\sigma=0.80$, T-test significant on the 0.01 level $)$ for the 11 VentureKick and $2.58(\sigma=0.78)$ for the ten venture leaders participants compared to a mean score of $1.99(\sigma=0.88$, T-test significant on the 0.05 level $)$ for the other 214 swissnex customers. This means that VentureKick and venture leader entrepreneurs are more successful than the average swissnex customers, with the VentureKick participants being even more successful. The small difference in success between venture leaders and VentureKick may also be explained by the longer lifetime of the companies engaged in the VentureKick programme, as VentureKick evaluates success of the companies enrolled in the programme repeatedly and hands out the funds incrementally.

\subsection{Venture leader entrepreneurs with a XING profile are more successful}

We found that on average the 63 venture leader participants who have a profile in XING are more successful (mean success of 3.37) than the 80 participants who do not have a XING profile (mean success of 3.15). However, this difference is not statistically significant. Nevertheless, this might indicate that just the simple act of participating in an online social network could be a predictor for successful startup founders.

Table 4 Success and network metrics of venture leaders who are ETH alumni

\begin{tabular}{lllccc}
\hline & & $N$ & Mean & Std. deviation & Std. error mean \\
\hline Success & Non-ETH & 39 & 3.10 & 1.209 & .194 \\
(sig. 0.01) & ETH & 24 & 3.79 & .833 & .170 \\
Degree_centrality & Non-ETH & 29 & 5.90 & 6.108 & 1.134 \\
(sig. 0.085) & ETH & 22 & 9.00 & 6.332 & 1.350 \\
Betweeness_centrality & Non-ETH & 29 & .02811 & .04514 & .00838 \\
(sig. 0.92) & ETH & 22 & .02917 & .03374 & .00719 \\
VC1_distance & Non-ETH & 27 & 2.41 & 1.010 & .194 \\
(sig. 0.12) & ETH & 22 & 1.77 & .685 & .146 \\
VC2_distance & Non-ETH & 27 & 2.78 & 1.013 & .195 \\
(sig.0.06) & ETH & 22 & 2.32 & .646 & .138 \\
\hline
\end{tabular}

\subsection{Swiss entrepreneurs with an ETH affiliation are more successful}

ETH alumni assume a dominant position in both the venture leader and VentureKick networks. Table 4 displays the key metrics. Among the success-ranked venture leaders in 
the founder network in Figure 6, ETH alumni are significantly more successful (mean success of 3.79 compared to 3.1 for non-ETH alumni).

The ETH alumni are also more central in the Swiss founder network shown in Figure 6, both by the average number of friends ( 9.0 compared to 5.9) and by betweenness centrality. They are also closer to both venture capitalists VC1 and VC2. However, shown in 9.1, the network position in the Swiss founder network (Figure 6) has no predictive power regarding business success.

\subsection{The more entrepreneurs are embedded into the ETH Alumni network, the more successful they are}

In the XING network of all ETH alumni, the founders' network position is significantly correlated with success by all network metrics. Figure 7 visually illustrates the cohesiveness of the ETH alumni founder network, with the founders shown as black dots. The more central the founders are within the ETH alumni network, the more successful they are. This is true for both degree centrality $\left(\mathrm{R}=0.394^{*}, \mathrm{~N}=27\right)$ and betweenness centrality $\left(\mathrm{R}=0.464^{*}, \mathrm{~N}=27\right)$. In the full XING network, successful ETH entrepreneurs also have more friends, measured as degree centrality. However, this result is not statistically significant.

We repeated this analysis for non-ETH alumni of the other 11 Swiss universities (St. Gallen, EPFL, Zurich, Basel, Bern, Fribourg, Neuchatel, Lugano, Lucerne, Geneva and Lausanne). Figure 8 displays the full network of all alumni of these universities, with the founders from Figure 6 shown as black dots. There is a (non-significant) correlation between success and betweenness of an entrepreneur in the network in Figure 8. Adding insights from 9.6, it seems that being an alumnus of ETH Zurich conveys a significant advantage to founding a startup.

\section{Discussion}

In this study, we showed that social network analysis is a useful tool for analysing the success of startup entrepreneurs. While we collected the networking data in the context of entrepreneurship coaching and training programmes, the results have broader applicability. It seems that business hubs and networking organisations can provide real value to founders of startups and academics alike. We also showed that social proximity to key influencers can be a good predictor of success, leading to the conclusion that it is not the quantity of (online) friends that matter, but their quality.

Even though we live in a mobile, technology-enabled world that conducts business virtually with increasing frequency, our results show that geographic proximity and face-to-face relationships still matter greatly in business success, especially in entrepreneurial ventures. On the theoretical level, these results confirm the value of pre-existing social capital acquired while attending a selective university or entrepreneurship programme for later business success. Our findings raise the question about whether it is possible to be a successful entrepreneur if one relies primarily on building relationships through virtual connections. Much further research is needed to investigate this fascinating research question in today's age of Facebook, Twitter, and YouTube. 
These findings prompt practical suggestions for operators of organisations, such as venture leaders, VentureKick, and swissnex, to further increase their (networking) efficiency: one goal would be to increase the density of the community network by identifying central hubs, and have special networking events connecting these community leaders, leading to increased connectivity and proximity of the entire network. Another idea might be to connect members of the unconnected groups in the e-mail network to create collaborative innovation networks (COINs, Gloor, 2006). This same concept could be implemented through a LinkedIn or Facebook-based matchmaking application, which would allow members to search for potential networking partners within the organisation's community.

On the practical level it seems that venture leaders, VentureKick, and swissnex are doing effective work supporting aspiring entrepreneurs and academics. Swiss scientists and innovators are prominently represented within the community; however, there is also a corresponding community of US and non-US entrepreneurs and academics who are connected to their Swiss counterparts thanks to swissnex. Our findings seem to indicate that the better these innovators are connected to each other and to key influencers, the more successful they are. The relative correlation between centrality and success leads to preliminary indications that the link of causality might go both ways. Innovators become more successful if they actively grow their network. On the other hand, with increasing success they also become ever more attractive as networking partners for the other members of the community, leading to a positively reinforced feedback loop: success begets success, the better connected members are, the more successful they become and the more successful they are, the better they get connected.

\section{Conclusions}

Our findings motivate recommendations for startup entrepreneurs from Switzerland and abroad. While it is frequently claimed that university alumni associations and business networking organisations help startup entrepreneurs succeed (Wolff and Moser, 2009; Bruderl and Preisendorfer, 1998), little research has been done on quantifying this effect for startup entrepreneurs. This is where our research breaks new ground. Studying at ETH - or another highly selective university - appears to provide clear advantages compared to studying at less selective universities, since it offers the strongest support network for aspiring entrepreneurs. When studying at ETH - or other highly selective universities, time and effort is well spent building strong links to other students and alumni from the same university. It also pays to participate in well-run startup coaching programmes - such as venture leaders and VentureKick, and to engage with business networking organisations - such as swissnex Boston; to grow a global business network. In ongoing research, we are studying a broader sample of entrepreneurs from large public and small private universities. On the theoretical level, these results confirm the value of preexisting social capital acquired while attending a selective university or entrepreneurship programme for later business success.

As social media appears to be an efficient tool for business networking, business networking hubs and mentoring organisations - such as swissnex Boston, venture leaders, and VentureKick - should fully integrate their social media campaign and presence in their core mission to support network building between entrepreneurs and academics. While our results are still preliminary, they illustrate that studying online 
social networks is an excellent way to better understand the effects of pre-existing social capital on business success, for instance through mutual interplay between business networking and entrepreneurship coaching organisations.

\section{Acknowledgements}

This project was supported by the Gebert Ruef Foundation, Switzerland, GRS - Projekt 051/09 'Measuring Startup-Success through SNA'. The authors would like to thank Pascal Marmier, director of swissnex Boston, Jordi Montserrat, co-managing director at VentureKick and regional manager of Venture Leaders, and Beat Schillig, managing director VentureKick, for their support.

\section{References}

Baum, J., Calabrese, T. and Silverman, B.S. (2000) 'Don't go it alone: alliance network composition and startups' performance in Canadian biotechnology', Strategic Management Journal, Vol. 21, No. 3, pp.267-294.

Bruderl, J. and Preisendorfer, P. (1998) 'Network support and the success of newly founded businesses’, Small Business Economics, Vol. 10, No. 3, pp.213-225.

Cohen, L., Frazzini, A. and Malloy, C. (2008) 'The small world of investing: board connections and mutual fund returns', The Journal of Political Economy, October, Vol. 116, No. 5, pp.951-979.

Ellison, N.B., Steinfeld, C. and Lampe, C. (2007) 'The benefits of Facebook 'friends': social capital and college students' use of online social network sites', Journal of Computer-mediated Communication, Vol. 12, No. 4, pp.1143-1168.

Fohlin, C. (1999) 'The rise of interlocking directorates in imperial Germany', Economic History Review, Vol. 52, No. 2, pp.307-333.

Gloor, P. (2006) Swarm Creativity. Competitive Advantage Through Collaborative Innovation Networks, Oxford University Press, New York, NY.

Gloor, P., Laubacher, R., Dynes, S. and Zhao, Y. (2003) 'Visualization of communication patterns in collaborative innovation networks: analysis of some W3C working groups', ACM CKIM International Conference on Information and Knowledge Management, 3-8 November, New Orleans.

Landis, J.R. and Koch, G.G. (1977) 'The measurement of observer agreement for categorical data', Biometrics, Vol. 33, No. 1, pp.159-174.

Mehra, A., Dixon, A.L., Robertson, B. and Brass, D.J. (2006) 'The social networks of leaders: implications for group performance and leader reputation', Organization Science, Vol. 17, No. 1, pp.64-79.

Nann, S., Krauss, J.S., Schober, M., Gloor, P., Fischbach, K. and Fuehres, H. (2010) The Power of Alumni Networks - Success of Startup Companies Correlates with Online Social Network Structure of its Founders, CCI Working Paper 2010-001 [online] http://papers.ssrn.com/sol3/ papers.cfm?abstract_id $=1534699$ (accessed November 2011).

O’Murchu, I., Breslin, J.G. and Decker, S. (2004) Online Social and Business Networking Communities, August 2004, DERI - Digital Enterprise Research Institute DERI Technical Report 2004-08-11.

Porter, K.A., Bunker Whittington, K.C. and Powell, W.W. (2005) 'The institutional embeddedness of high-tech regions: relational foundations of the Boston biotechnology community', in Breschi, S. and Malerba, F. (Eds.): Clusters, Networks, and Innovation, pp.261-296, Oxford University Press, Oxford, UK. 
Raz, O. and Gloor, P. (2007) 'Size really matters - new insights for startup's survival', Management Science, February, Vol. 53, No. 2, pp.169-177.

Schilling, M.A. and Phelps, C.C. (2007) 'Interfirm collaboration networks: the impact of small world connectivity on firm innovation', Management Science, Vol. 53, No. 7, pp.1113-1126.

Uzzi, B. (1997) 'Social structure and competition in interfirm networks: the paradoxon of embeddedness', Administrative Science Quarterly, Vol. 42, No. 1, pp.35-67.

Wasserman, S. and Faust, K. (1994) Social Network Analysis, Cambridge University Press, Cambridge, UK.

Wolff, H. and Moser, K. (2009) 'Effects of networking on career success: a longitudinal study', Journal of Applied Psychology, January, Vol. 94, No. 1, pp.196-206, doi: 10.1037/a0013350.

\section{Notes}

1 Actor degree is informally defined as the number of friends of an actor, betweenness centrality is informally defined at the likelihood of an actor to be on all shortest paths between any two network nodes (Wasserman and Faust, 1994).

$2 * *$ means correlation $\mathrm{R}$ is significant on the 0.01 level, * means $\mathrm{R}$ is significant on the 0.05 level. 